\title{
REVISITED TO THE RELATIONSHIP BETWEEN THE FREE AND TOTAL CHLORIDE DIFFUSIVITY IN CONCRETE
}

\author{
Ming-Te Liang \\ Department of Civil Engineering, China University of Science and Technology, Taipei, Taiwan, R.O.C, \\ mtliang@cc.cust.edu.tw \\ Ran Huang \\ Department of Harbor and River Engineering, National Taiwan Ocean University, Keelung, Taiwan, R.O.C \\ Hao-Yuan Jheng \\ Department of Harbor and River Engineering, National Taiwan Ocean University, Keelung, Taiwan, R.O.C
}

Follow this and additional works at: https://jmstt.ntou.edu.tw/journal

Part of the Civil and Environmental Engineering Commons

\section{Recommended Citation}

Liang, Ming-Te; Huang, Ran; and Jheng, Hao-Yuan (2010) "REVISITED TO THE RELATIONSHIP BETWEEN THE FREE AND TOTAL CHLORIDE DIFFUSIVITY IN CONCRETE," Journal of Marine Science and Technology. Vol. 18: Iss. 3, Article 16.

DOI: $10.51400 / 2709-6998.1892$

Available at: https://jmstt.ntou.edu.tw/journal/vol18/iss3/16

This Research Article is brought to you for free and open access by Journal of Marine Science and Technology. It has been accepted for inclusion in Journal of Marine Science and Technology by an authorized editor of Journal of Marine Science and Technology. 
REVISITED TO THE RELATIONSHIP BETWEEN THE FREE AND TOTAL CHLORIDE DIFFUSIVITY IN CONCRETE

Acknowledgements

The authors gratefully acknowledge the support provided for this research by the National Science Council, Republic of China, under contract No. NSC 96-2221-E-157-002. 


\title{
REVISITED TO THE RELATIONSHIP BETWEEN THE FREE AND TOTAL CHLORIDE DIFFUSIVITY IN CONCRETE
}

\author{
Ming-Te Liang*, Ran Huang**, and Hao-Yuan Jheng**
}

Key words: chloride, concrete, diffusion, diffusivity, durability.

\begin{abstract}
The main purpose of this paper is provided the theoretical elucidation and parameter investigation for the experimental results performed by Lu et al. [Relationship between the free and total chloride diffusivity in concrete, Cement and Concrete Research, 32(2) 323 326 (2002)]. The analytical solution of Fick's second law of linear diffusion in a semi-infinite quasi-homogeneous and isotropic concrete with initial and boundary conditions is used to curve fitting the experimental results and to find the relevant parameters such as the total and free chloride concentrations and diffusivities. The total chloride diffusivity is 2.8 times the free one. It seems plausible to assume that bound chloride content in concrete is about two times that of the free one.
\end{abstract}

\section{INTRODUCTION}

Chloride-induced corrosion is a major factor which causes the deterioration of concrete or reinforced concrete (RC) structures exposed to a marine environment or to deicing salt. Under the environment condition of chloride contamination, the chloride binding capacity of concrete may affect the durability of concrete $[3,8,16,17]$. The mineral admixtures such as fly ash and slag may reduce the diffusivity or increase the chloride binding capacity in concrete. It is well-known that the chemically bound and physically adsorbed chloride can not harm the corrosion of steel in concrete. Mere the free chloride can initiate the corrosion of reinforcement. The free chloride means the water-soluble chloride in concrete while the total chloride means the acid-soluble chloride in concrete. The bound chloride refers to the total chloride minus the free one.

Paper submitted 12/05/08; accepted 09/22/09. Author for correspondence: Ming-Te Liang (e-mail: mtliang@cc.cust.edu.tw).

*Department of Civil Engineering, China University of Science and Technology, Taipei, Taiwan, R.O.C.

**Department of Harbor and River Engineering, National Taiwan Ocean University, Keelung, Taiwan, R.O.C.
Relationship between total, free, and bound chloride ions in concrete are very important for the development of model for service life predictions of RC with respect to reinforcement corrosion. Tang and Nilsson [17] used both the Freundlich adsorption isotherm at high free chloride concentrations ( $>0.01 \mathrm{~mol} / \mathrm{l}$ ) and Langmuir adsorption isotherm at low free chloride concentration $(<0.05 \mathrm{~mol} / \mathrm{l})$ to describe the relationship between the bound chloride and the free chloride. Nilsson et al. [11] defined a binding isotherm which gives the bound and total amount of chlorides as a function of the free chloride concentration at a constant temperature. They also defined that binding capacity $=\partial C_{b} / \partial C_{f}$, where $C_{b}$ and $C_{f}$ are respectively the bound and free chloride, is the capacity of a material to bind chloride when the ion concentration changes. This is the slope of a binding isotherm. Sandberg [15] pointed out that chloride bind in hydrated cement pastes usually leads to a nonlinear relationship between free and bound chloride. In consequence of the nonlinear chloride binding, the relationship between free and total chloride is also nonlinear.

The magnitude of chloride diffusivity in concrete not only can contemplate the permeability of concrete, but also can be made use of service life prediction of concrete or RC structures as the model is based on the corrosion of reinforcement in concrete [6]. Nilsson et al. [12] predicted the service life of concrete or RC structures based on age-dependent chloride diffusivity. Using non-steady state tests, Francy and Francois [4] calculated the evolution of chloride diffusivity from total and free chloride profiles of mortars. Diffusivity was found to decrease whereas free chloride concentration increases, however, the influence is notable only for very low concentrations. Lu et al. [7] used an electrochemical method to set up the relationship between the free and total chloride diffusivity in concrete. They found that the total chloride diffusivity is about 2.2 3.4 times the free one. They also assumed that the bound chloride content in concrete is about two times that of the free one. Although the relationship between the free and total chloride diffusivity in concrete had been experimentally studied by Lu et al. [7], theoretical background has not been established by them. This is a notable shortcoming, because the use of experimented study may have resulted in underestimation or overestimation of the free and total chloride diffusivity. 
The work presented here focuses on the theoretical study the relationship between the free and total chloride diffusivity in concrete based on the theory of Fick's second law of linear diffusion and the experimental results done by Lu et al. [7]. The results of present study may be very useful when predicting the service life of concrete and comparing the permeability of concrete with different mineral admixture when employing the chloride diffusivity as permeability index.

\section{THEORETICAL BASIS}

Based on the ionic distribution in cement-based systems, the relationship between the free and total chloride diffusivity in concrete was experimentally established by Lu et al. [7]. A successful diffusion model needed is set up to elucidate the experimental results done by Lu et al. [7] and describes below.

The relation among total, bound, and free chloride concentration in concrete is expressed by $[9,16]$

$$
C_{t}=C_{b}+\omega_{e} C_{f}
$$

where $C_{t}$ is the total chloride concentration, $C_{b}$ is the concentration of the bound chloride, $C_{f}$ is the free chloride concentration, and $\omega_{e}$ is the evaporable water content.

According to mass conservation and considering an unidirectional diffusion in a quasi-homogeneous and isotropic concrete, Eq. (1) may be changed as

$$
\frac{\partial C_{t}}{\partial t}=\frac{\partial C_{b}}{\partial t}+\omega_{e} \frac{\partial C_{f}}{\partial t}=-\frac{\omega_{e}}{\varepsilon} \frac{\partial J}{\partial x}
$$

where $J$ is the flux, $t$ is the diffusion time, $x$ is the diffusion distance, and $\varepsilon$ is the volume fraction of the water in which diffusion occurs.

The diffusing chloride ions are physically absorbed and chemically bound on to pore surfaces within the cement matrix [10]. Pereira and Hegedus [14] pointed out that chloride binding is a very fast process compared with diffusion and suggested that the instantaneous relationship between bound and free chloride may be approximated by the Langmuir adsorption isotherm, as stated by

$$
C_{b}=\frac{\alpha C_{f}}{1+\beta C_{f}}
$$

where $\alpha$ and $\beta$ are binding constants that very according to concrete binder composition. Funahashi [5] reported that the bound chloride may be almost linearly related to free or total chloride. Accordingly, this may be mathematically treated as a special case of (3) in which $\beta$ is zero.

During diffusion process in the cement-based system, a hydroxyl ion may also be bound to or desorbed from the cement matrix. Its binding characteristics are quantitatively difficult to decide and will be neglected in the present study.
The flux can be determined by Fick's first law of diffusion with a constant diffusivity, $D$, in the pore solution [1] and is expressed by

$$
J=-\varepsilon D \frac{\partial C_{f}}{\partial x}
$$

From (2) and (4), we obtain Fick's second law of diffusion

$$
\frac{\partial C_{f}}{\partial t}=D \frac{\partial^{2} C_{f}}{\partial x^{2}}
$$

for the concentration profile in the pore solution, or

$$
\frac{\partial C_{t}}{\partial t}=D \frac{\partial^{2} C_{t}}{\partial x^{2}}
$$

for total ionic profile.

The chloride ions with binding characteristics may be approximated by the Langmuir adsorption isotherm [3]. From (2), (3), and (4), the chloride concentration profile would be governed by

$$
\left[1+\frac{\alpha}{\omega_{e}\left(1+\beta C_{f}\right)^{2}}\right] \frac{\partial C_{f}}{\partial t}=D \frac{\partial^{2} C_{f}}{\partial x^{2}}
$$

If the value of $\beta$ is zero, linear adsorption, Eq. (7) would be simplified to

$$
\frac{\partial C_{f}}{\partial t}=\frac{\omega_{e} D}{\alpha+\omega_{e}} \frac{\partial^{2} C_{f}}{\partial x^{2}}=D_{f} \frac{\partial^{2} C_{f}}{\partial x^{2}}
$$

for the free chloride concentration profile, in which $D_{f}$ is the free chloride diffusivity in concrete, or

$$
\frac{\partial C_{t}}{\partial t}=\frac{\omega_{e} D}{\alpha+\omega_{e}} \frac{\partial^{2} C_{t}}{\partial x^{2}}=D_{t} \frac{\partial^{2} C_{t}}{\partial x^{2}}
$$

for the total chloride concentration profile.

It is noteworthy that both the free and total chloride profiles with Fick's second law of linear diffusion yields the same value for the apparent diffusivity $\left(D_{f}=D_{t}\right)$, i.e., $\omega_{e} /\left(\alpha+\omega_{e}\right)$ times the value of $D$.

First, Fick's second law of linear diffusion equation in a semi-infinite quasi homogeneous and isotropic concrete is used to state the free chloride concentration profile. Equation (8) with initial boundary conditions can be expressed as [1]

$$
\frac{\partial C_{f}}{\partial t}=D_{f} \frac{\partial^{2} C_{f}}{\partial x^{2}}, D_{f}=\text { constant }
$$




$$
\begin{gathered}
C_{f}(x, 0)=0 \\
C_{f}(0, t)=C_{0 f} \\
C_{f}(x \rightarrow \infty, t)=0
\end{gathered}
$$

where $C_{0 f}$ is the free chloride concentration on the concrete surface.

Using the method of Laplace transform [13], the analytic solution of (10) can be obtained

$$
C_{f}(x, t)=C_{0 f}\left[1-\operatorname{erf}\left(\frac{x}{\sqrt{4 D_{f} t}}\right)\right]=C_{0 f} \operatorname{erfc}\left(\frac{x}{\sqrt{4 D_{f} t}}\right)
$$

where erf is the error function and erfc is the complementary error function.

If setting $x=$ constant $=\xi$, then (11) is changed as

$$
D_{f}(t)=\frac{1}{t}\left[\frac{\xi}{2 \operatorname{erfc}^{-1}\left(\frac{C_{f}(t)}{C_{0 f}}\right)}\right]^{2}
$$

where $\operatorname{erfc}^{-1}$ is the inverse of complementary error function.

If putting $t=$ constant $=\eta$, then (11) may be written as

$$
D_{f}(x)=x^{2}\left\{\frac{1}{\eta}\left[\frac{1}{\operatorname{erfc}^{-1}\left(\frac{C_{f}(x)}{C_{0 f}}\right)}\right]^{2}\right\}
$$

Finally, Fick's second law of linear diffusion equation in a semi-infinite quasi-homogeneous and isotropic concrete is employed to describe the total chloride concentration profile (9) with initial and boundary conditions and can be put forward as

$$
\begin{gathered}
\frac{\partial C_{t}}{\partial t}=D_{t} \frac{\partial^{2} C_{t}}{\partial x^{2}}, D_{t}=\text { constant } \\
C_{t}(x, 0)=0 \\
C_{t}(0, t)=C_{0 t} \\
C_{t}(x \rightarrow \infty, t)=0
\end{gathered}
$$

\begin{tabular}{|c|c|c|c|c|c|}
\hline \multirow[t]{2}{*}{ Specimen } & \multirow{2}{*}{$\begin{array}{c}\text { Time } \\
t \text { (days) }\end{array}$} & \multirow{2}{*}{$\begin{array}{c}\begin{array}{c}\text { Surface } \\
\text { chloride }\end{array} \\
C_{0 f}(\%)\end{array}$} & \multirow{2}{*}{$\begin{array}{c}\text { Concen- } \\
\text { tration } \\
C_{0 t}(\%)\end{array}$} & \multicolumn{2}{|c|}{ Diffusivity } \\
\hline & & & & $\begin{array}{c}D_{f} \\
\left(10^{-8} \mathrm{~cm}^{2} / \mathrm{s}\right)\end{array}$ & $\begin{array}{c}D_{t} \\
\left(10^{-8} \mathrm{~cm}^{2} / \mathrm{s}\right)\end{array}$ \\
\hline $\mathrm{C} 1$ & 90 & 0.300 & 0.370 & 0.105944 & 0.286335 \\
\hline $\mathrm{C} 3$ & 90 & 0.390 & 0.455 & 0.189822 & 0.531713 \\
\hline $\mathrm{C} 5$ & 90 & 0.450 & 0.510 & 0.220568 & 0.617838 \\
\hline D4 & 90 & 0.200 & 0.380 & 0.026022 & 0.072890 \\
\hline E6 & 90 & 0.305 & 0.375 & 0.087700 & 0.245658 \\
\hline
\end{tabular}

In a similar way, the analytic solution of (14) can be stated as
Table 1. Theoretically calculated input parameters for chloride profile.

$C_{t}(x, t)=C_{0 t}\left[1-\operatorname{erf}\left(\frac{x}{\sqrt{4 D_{t} t}}\right)\right]=C_{0 t} \operatorname{erfc}\left(\frac{x}{\sqrt{4 D_{t} t}}\right)$

If inserting $x=$ constant $=\xi$, then (15) may be expressed as

$$
D_{t}(t)=\frac{1}{t}\left[\frac{\xi}{2 \operatorname{erfc}^{-1}\left(\frac{C_{t}(t)}{C_{0 t}}\right)}\right]^{2}
$$

If setting $t=$ constant $=\eta$, then (15) may be represented as

$$
D_{t}(x)=x^{2}\left\{\frac{1}{\eta}\left[\frac{1}{\operatorname{erfc}^{-1}\left(\frac{C_{t}(x)}{C_{0 t}}\right)}\right]^{2}\right\}
$$

\section{AVAILABLE EXPERIMENTAL DATA}

The concrete mixes are listed in Table 1 in Ref. [7]. Using these concrete specimens, Lu et al. [7] applied an electrochemical method to determine the free and total chloride concentrations. They separately displayed the free and total chloride concentration profiles in some $\mathrm{C}$ service specimens and in fly ash and slag concrete. Lu et al. [7] also used Fick's second law to calculate the free and total chloride diffusivities in concrete. They depicted the relationship between free and total chloride diffusivity in concrete. The ratio of $D_{t} / D_{f}$ versus experimental data has also been shown in Ref. [7].

\section{RESULTS AND DISCUSSION}

In order to compare the theoretical predictions with ex- 


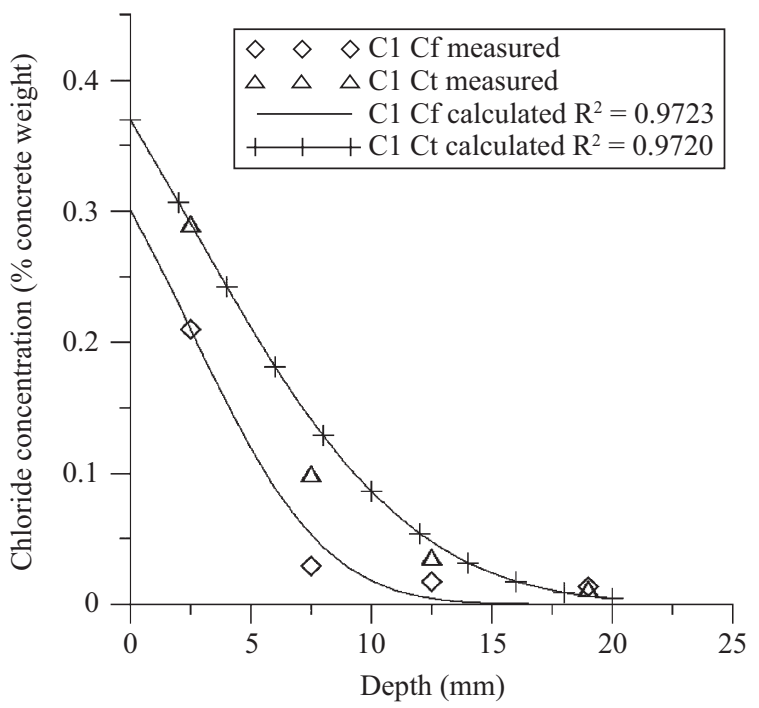

Fig. 1. Free and total chloride concentration versus depth for $\mathrm{C} 1$ specimen.

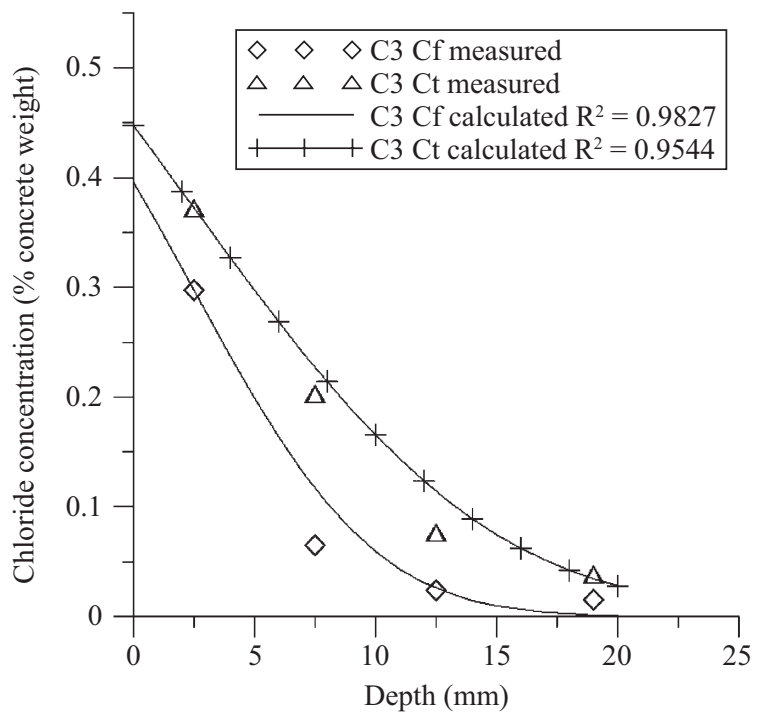

Fig. 2. Free and total chloride concentration versus depth for $\mathrm{C} 3$ specimen.

perimental results, the software package "Mathematica" [20] is used to calculate the theoretical formulas employed in this study.

Substituting parameters listed in Table 1 into Eqs. (11) and (15), we may obtain the calculated free and total chloride concentrations versus depth for $\mathrm{C} 1, \mathrm{C} 3, \mathrm{C} 5, \mathrm{D} 4$, and E6 as shown Figs. 1-5 for comparing with measured results [7]. It is remarkable that the predicted and measured chloride profiles are coincided very well. In the case of plain concrete (Figs. 1-3), bound chloride content in concrete increases with increasing w/c. Both the chloride concentration and the bound chloride content of concrete decrease with increasing depth. If compared Figs. 1-3 and Figs. 4-5, with greater depth into concrete, then the bound chloride of the blended cement concrete

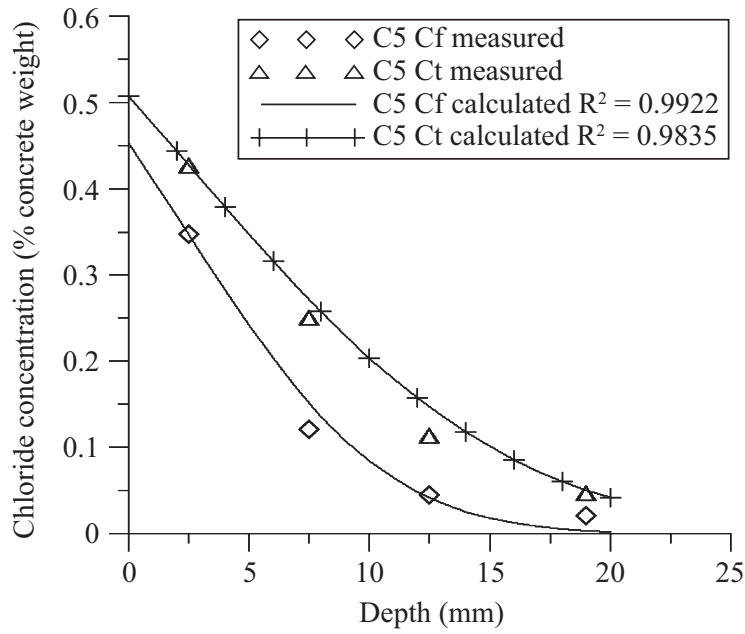

Fig. 3. Free and total chloride concentration versus depth for $\mathrm{C5}$ specimen.

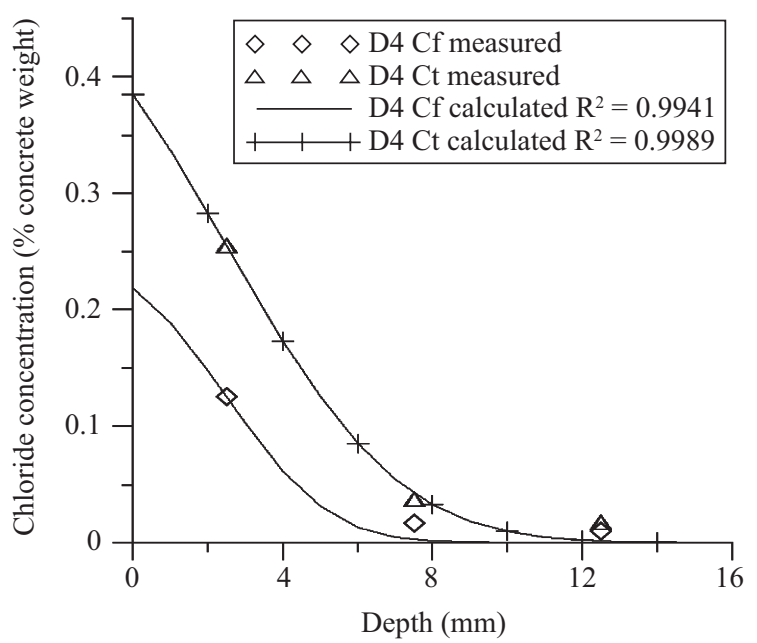

Fig. 4. Free and total chloride concentration versus depth in fly ash concrete for D4 specimen.

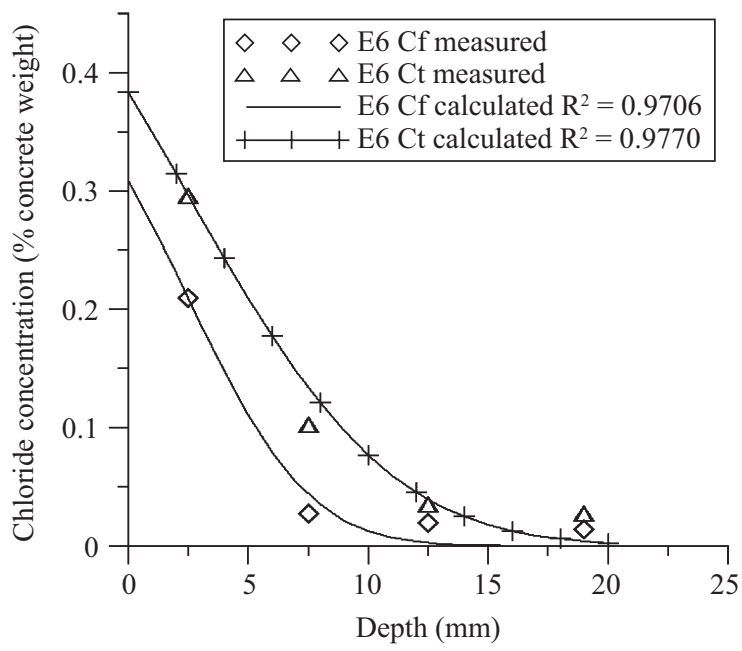

Fig. 5. Free and total chloride concentration versus depth in slag concrete for E6 specimen. 
Table 2. Theoretically calculated input diffusivity versus time and depth.

\begin{tabular}{ccccccc}
\hline $\begin{array}{c}\text { Speci- } \\
\text { men }\end{array}$ & Depth & Time & $\begin{array}{c}\text { Free } \\
\text { chloride }\end{array}$ & $\begin{array}{c}\text { concen- } \\
\text { tration }\end{array}$ & $\begin{array}{c}\text { Total } \\
\text { chloride }\end{array}$ & $\begin{array}{c}\text { concen- } \\
\text { tration }\end{array}$ \\
& $x(\mathrm{~cm})$ & $t($ days $)$ & $C_{f}(t)(\%)$ & $C_{0 f}(\%)$ & $C_{t}(t)(\%)$ & $C_{0 t}(\%)$ \\
\hline $\mathrm{C} 1$ & 2.5 & 90 & 0.21130 & 0.29038 & 0.105944 & 0.286335 \\
$\mathrm{C} 3$ & 2.5 & 90 & 0.29736 & 0.37249 & 0.189822 & 0.531713 \\
$\mathrm{C} 5$ & 2.5 & 90 & 0.34717 & 0.42723 & 0.220568 & 0.617838 \\
$\mathrm{D} 4$ & 2.5 & 90 & 0.20978 & 0.29674 & 0.087700 & 0.245658 \\
$\mathrm{E} 6$ & 2.5 & 90 & 0.12490 & 0.25486 & 0.026022 & 0.072889 \\
\hline
\end{tabular}

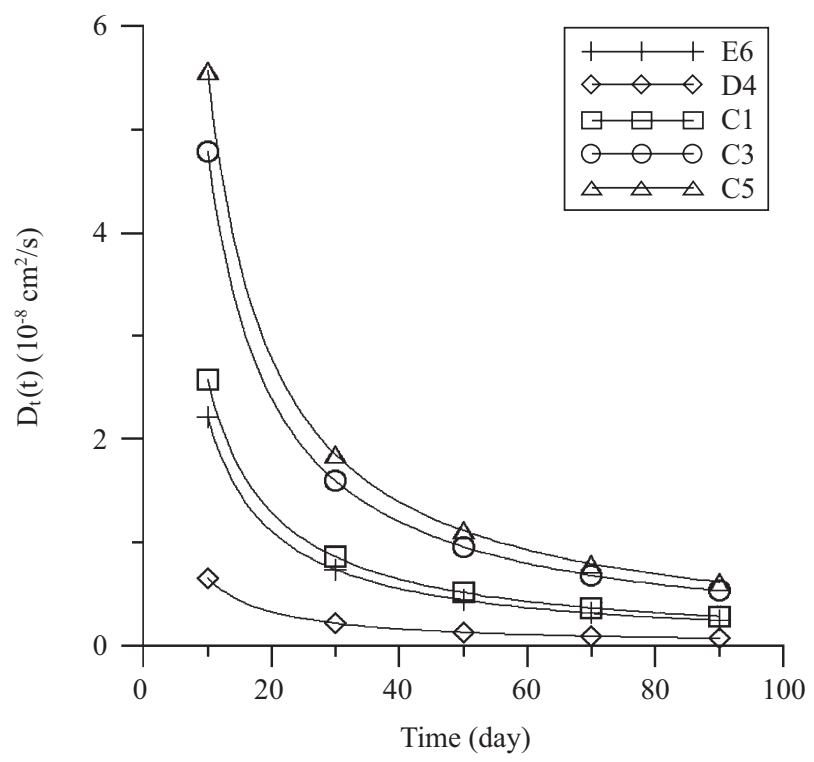

Fig. 6. Free chloride diffusivity versus time.

decreases significantly. Furthermore, at greater depths in concrete, the free chloride concentration of the plain concrete is significantly higher than that for the blended cement concrete. This would tend to promote more chloride ions binding. Moreover, the impermeability of blended cement concrete at higher depths reduces the availability of calcium aluminates for reaction with chloride ions. For slag concrete this is offset by the extent to which additional aluminates is available in the slag. This study suggests that the permeability of concrete is much more significant in determining free chloride concentration than the binding capacity of the cement matrix.

Inserting parameters recorded in Table 2 into (12) and (16), we may gain the relationship between the free and total diffusivity and time as illustrated in Figs. 6 and 7, respectively. From Figs. 6 and 7, it is worthy to point out that both the free and total diffusivities are inverse proportional the chloride penetration time. With increasing chloride penetration to time in concrete, both the free and total chloride diffusivities of the plain concrete are significantly faster than that for the blended cement concrete.

Putting parameters listed in Table 2 into (13) and (17)

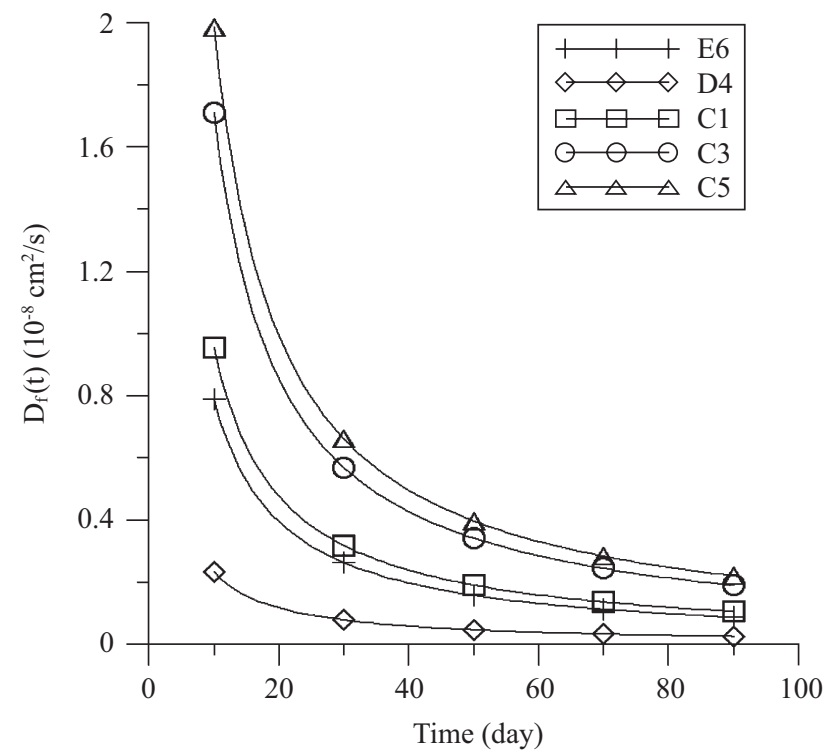

Fig. 7. Total chloride diffusivity versus time.

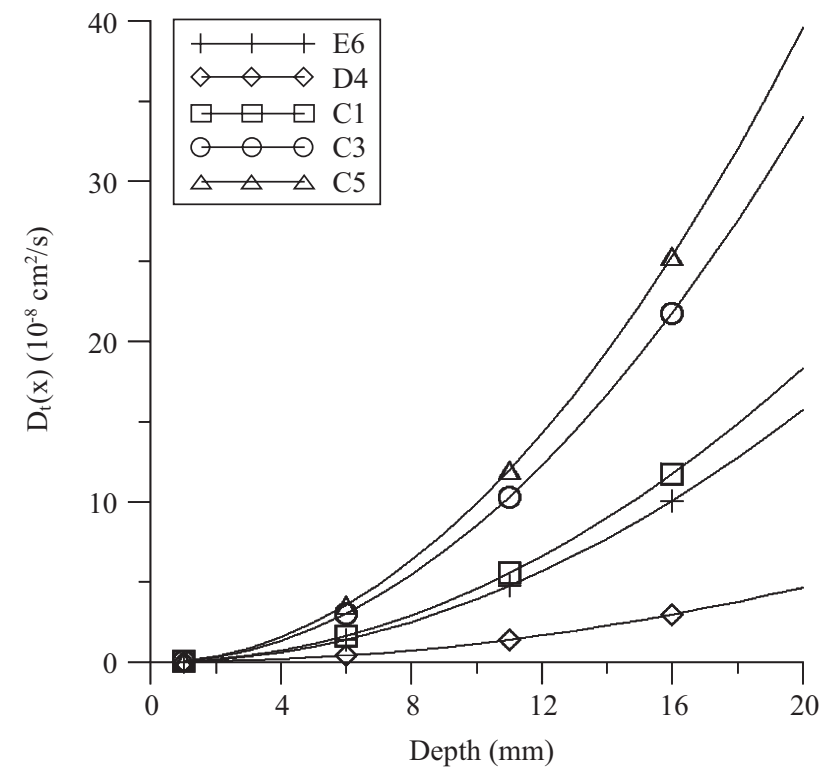

Fig. 8. Free chloride diffusivity versus depth.

we may attain the relationship between the free and total diffusivity and depth as depicted in Figs. 8 and 9, respectively. From Figs. 8 and 9, it is very obvious that both the fee and total diffusivities are proportional to the square of chloride penetration depth. At greater depths in concrete, both the free and total diffusivities of the plain concrete are significantly faster than that for the blended cement concrete.

Sergi et al. [16] used respectively (7) and (8) to compare the predicted results with experimental data as shown in Fig. 2 in Ref. [16]. They obtained that the diffusivities of the free chloride with $\beta \neq 0$ and $\beta=0$ were $D_{f}=4.28 \times 10^{-7} \mathrm{~cm}^{2} / \mathrm{s}$ and $D_{f}=1.40 \times 10^{-7} \mathrm{~cm}^{2} / \mathrm{s}$, respectively. It is very obvious that 


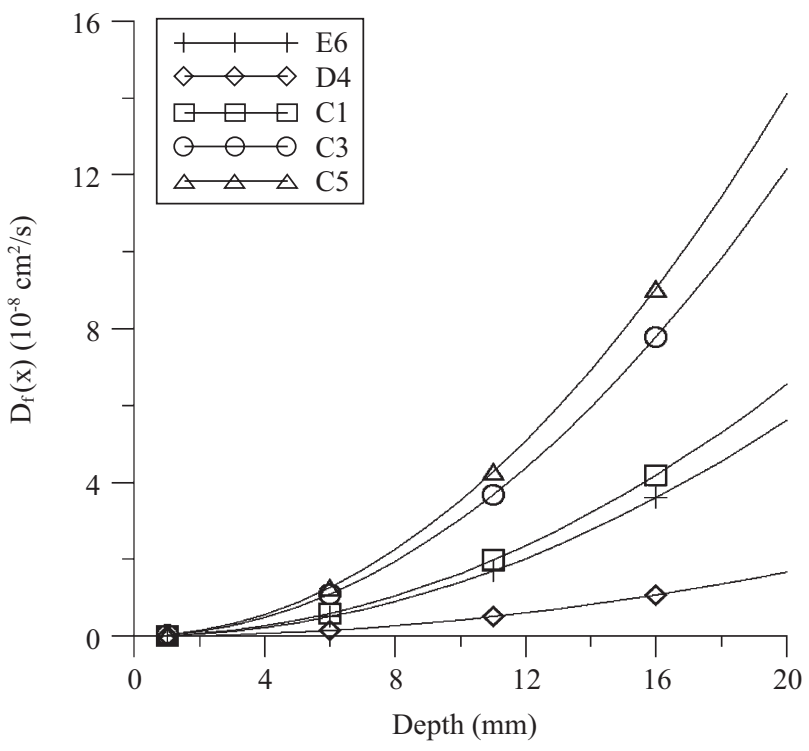

Fig. 9. Total chloride diffusivity versus depth.

the diffusivity of free chloride with $\beta \neq 0$ is about three times that of the free one with $\beta=0$. Based on the experimental data obtained by Sergi et al. [16], Tumidajski [18] used simultaneous chloride diffusion and chemical reaction to determine the total chloride diffusivity. The mathematical model applied by Tumidajski [18] is described as follows.

$$
\begin{gathered}
\frac{\partial C_{t}}{\partial t}=D_{t} \frac{\partial^{2} C_{t}}{\partial x^{2}}-k C_{t} \\
C_{t}(x, 0)=0 \\
C_{t}(0, t)=C_{0 t} \\
C_{t}(x \rightarrow \infty, t)=0
\end{gathered}
$$

where $k$ is the velocity constant of the chemical reaction between solute and medium.

The analytical solution derived by Danckmerts [2] to (18) is

$$
\begin{aligned}
C_{t}(x, t)= & \frac{1}{2} C_{0 t}\left[\exp \left(-x \sqrt{\frac{k}{D_{t}}}\right) \operatorname{erfc}\left(\frac{x}{\sqrt{4 D_{t} t}}-\sqrt{k t}\right)\right. \\
& \left.+\exp \left(x \sqrt{\frac{k}{D_{t}}}\right) \operatorname{erfc}\left(\frac{x}{\sqrt{4 D_{t} t}}+\sqrt{k t}\right)\right]
\end{aligned}
$$

Tumidajski [18] employed (19) to fit the experimental data obtain by Sergi et al. [16] as shown in Fig. 1 in Ref. [18]. He

\begin{tabular}{|c|c|c|c|c|c|}
\hline \multirow{2}{*}{$\begin{array}{l}\text { Speci- } \\
\text { men }\end{array}$} & \multirow{2}{*}{$\begin{array}{c}\text { Time } \\
t \text { (days) }\end{array}$} & \multirow{2}{*}{$\begin{array}{c}\text { Surface } \\
\text { chloride } \\
C_{0 f}(\%)\end{array}$} & \multirow{2}{*}{$\begin{array}{l}\text { concen- } \\
\text { tration } \\
C_{0 t}(\%)\end{array}$} & \multicolumn{2}{|c|}{ Diffusivity } \\
\hline & & & & $\begin{array}{c}D_{f} \\
\left(10^{-8} \mathrm{~cm}^{2} / \mathrm{s}\right)\end{array}$ & $\begin{array}{c}D_{t} \\
\left(10^{-8} \mathrm{~cm}^{2} / \mathrm{s}\right)\end{array}$ \\
\hline $\mathrm{C} 1$ & 85 & 0.300 & 0.370 & 0.112175 & 0.303178 \\
\hline $\mathrm{C} 3$ & 85 & 0.390 & 0.455 & 0.209880 & 0.562991 \\
\hline C5 & 85 & 0.450 & 0.510 & 0.233543 & 0.654181 \\
\hline D4 & 85 & 0.200 & 0.380 & 0.027552 & 0.077177 \\
\hline E6 & 85 & 0.305 & 0.375 & 0.092859 & 0.260108 \\
\hline
\end{tabular}
obtained that the diffusivity of total chloride was $D_{t}=3.95 \times$ $10^{-7} \mathrm{~cm}^{2} / \mathrm{s}$. Thus, we have $D_{t} / D_{f}=3.95 \times 10^{-7} \mathrm{~cm}^{2} / \mathrm{s} / 1.40 \times$ $10^{-7} \mathrm{~cm}^{2} / \mathrm{s}=2.82$ (see Table 1 in Ref. [18]).
Table 3. Theoretically calculated parameters for chloride profile.

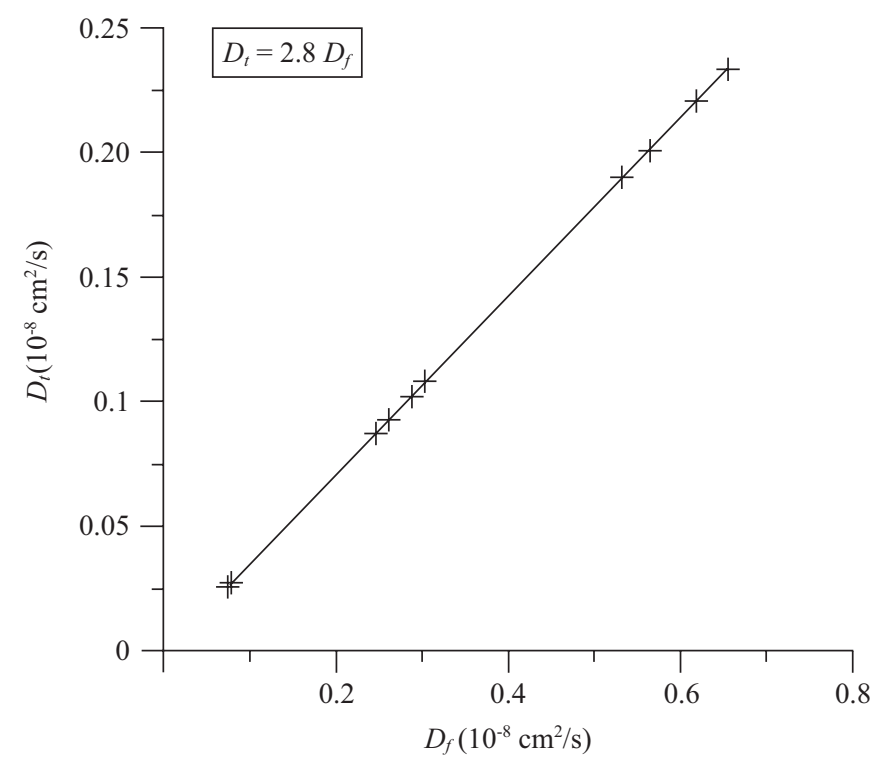

Fig. 10. The relationship between free and total chloride diffusivity in concrete.

Based on the values of $D_{f}$ and $D_{t}$ at $t=90$ days (see Table 1) and $t=85$ days (see Table 3 ), Fig. 10 shows the relationship between the free and total chloride diffusivities in concrete. It is found that the total chloride diffusivity is 2.8 times to the free chloride diffusivity. Lu et al. [10] assumed that the total chloride diffusivity is approximate three times free chloride diffusivity. This means that the bound chloride content is around two times the free one. Tuutti [19] suggested a relationship for bound chloride in terms of a factor $K$ for concrete immersed in a solution of $3 \%$ sodium chloride as

bound chloride $=K$ (free chloride), $K=2$ (this study)

Both the predicted data of this study and the measured results done by Lu et al. [7] do agree well with (20). It is worthy to enhance that this relationship may be very useful when predicting the service life of concrete or comparing the permeability of concrete. 


\section{CONCLUSIONS}

The theoretical basis has been established. Based on the theoretical calculation in this study and the measured results obtained by $\mathrm{Lu}$ et al. [7], some important conclusions are drawn out in the following:

1. The analytical solution of Fick's second law of linear diffusion equation in a quai-homogeneous and isotropic concrete with initial and boundary conditions can be theoretically elucidated the experimental results done by $\mathrm{Lu}$ et al. [7] about the relationship between the free and total chloride diffusivity in concrete.

2. Bound chloride content in plain concrete increases with increasing $\mathrm{W} / \mathrm{C}$.

3. As the chloride penetration depth in concrete increases, the free chloride concentration of the plain concrete is strikingly higher than that for the blended cement concrete.

4. As the chloride penetration depth or time in concrete increase, both the free and total chloride diffusivities of the plain concrete are significantly faster than that for the blended cement concrete.

5. The total chloride diffusivity is around 2.8 times that of the free chloride in concrete. This may be assumed that the bound chloride content in concrete is about two times that of the free one. This relationship may be extremely useful when predicting the service life of concrete or comparing the permeability of concrete with different mineral admixture when making use of the chloride diffusivity as permeability index.

\section{ACKNOWLEDGMENTS}

The authors gratefully acknowledge the support provided for this research by the National Science Council, Republic of China, under contract No. NSC 96-2221-E-157-002.

\section{REFERENCES}

1. Crank, J., The Mathematics of Diffusion, Second Edition, Oxford University Press, Oxford (1975).

2. Danckwerts, P. V., "Absorption by simultaneous diffusion and chemical reaction," Transactions of the Faraday Society, Vol. 46, pp. 300-304 (1950).

3. Dhir, R. K. and Byars, E. A., "PFA concrete: chloride diffusion rates,"
Magazine of Concrete Research, Vol. 45, No. 162, pp. 1-9 (1993).

4. Francy, O. and Francois, R., "Measuring chloride diffusion coefficients from non-steady state diffusion teats," Cement and Concrete Research, Vol. 28, No. 7, pp. 947-953 (1998).

5. Funahashi, M., "Predicting corrosion-free service life of a concrete structure in a chloride environment," ACI Materials Journal, Vol. 87, No. 6, pp. 581-587 (1990).

6. Lu. X. Y., "Application of the Nernst-Einstein equation to concrete," Cement and Concrete Research, Vol. 27, No. 2, pp. 293-302 (1997).

7. Lu, X. Y., Li, C. L., and Zhang, H. X., "Relationship between the free and total chloride diffusivity in concrete," Cement and Concrete Research, Vol. 32, No. 2, pp. 323-326 (2002).

8. Mangat, P. S. and Molloy, B. T., "Chloride binding in concrete containing PFA, GBS or silica fume under sea water exposure," Magazine of Concrete Research, Vol. 47, No. 171, pp. 129-141 (1995).

9. Martin-Perez, B., Zibara, H., Hooton, R. D., and Thomas, M. D. A., "A study of the effect of chloride binding on service life prediction," Cement and Concrete Research, Vol. 30, No. 8, pp. 1215-1223 (2000).

10. Midyley, H. G. and Iiiston, J. M., "The penetration of chloride into hardened cement pastes," Cement and Concrete Research, Vol. 14, No. 4, pp. 564-558 (1984).

11. Nilsson, L.-O., Poulsen, E., Sandberg, P., Sorensen, H. E., and Klinghoffer, O., Chloride Penetration into Concrete, State-of-the-Art, Report No. 53, The Danish Road Directorate (1996).

12. Nilsson, L.-O., Sandberg, P., Poulsen, E., Tang, L. P., Andersen, A., and Frederiksen, J. M., A System for Estimation of Chloride Ingress into Concrete, Theoretical Background, Report No. 83, The Danish Road Directorate (1997).

13. O'Neil, P. V., Advanced Engineering Mathematics, 5th Edition, Thomson Brooks/Cole, United States (2003).

14. Pereira, C. J. and Hegedus, L. L., "Diffusion and reaction of chloride ions in porous concrete," European Federation of Chemical Engineering, EFCE publication series No. 37, ISCRE 8, Proceedings of the 8th International Symposium on Chemical Reaction Engineering, pp. 427-438 (1984).

15. Sandberg, P., "Studies of chloride binding in concrete exposed in a marine environment," Cement and Concrete Research, Vol. 29, No. 3, pp. 473-477 (1999).

16. Sergi, G., Yu, S. W., and Page, C. L., "Diffusion of chloride and hydroxyl ions in cementitious materials exposed to a saline environment," Magazine of Concrete Research, Vol. 44, No. 158, pp. 63-69 (1992).

17. Tang, L. P. and Nilsson, L.-O., "Chloride binding capacity and binding isotherms of OPC pastes and mortars," Cement and Concrete Research, Vol. 23, No. 2, pp. 247-253 (1993).

18. Tumidajski, P. J., “Application of Danckwerts' solution to simultaneous diffusion and chemical reaction in concrete," Cement and Concrete Research, Vol. 26, No. 5, pp. 697-700 (1996).

19. Tuutti, K., Corrosion of Steel in Concrete, Swedish Cement and Concrete Research Institute, Stockholm (1982).

20. Wolfram Research, Mathematica User Manual, Version 4.0, 100 Trade Center Drive, Champaign, IL 61820-7237, USA (1999). 